\title{
Photomask Patterning for Slope-Form Deep Etching Using Deep-Reactive-Ion Etching and Gradation Exposure
}

\author{
Masaki Yamaguchi* and Yuki Nakayama \\ Graduate School of Engineering, Iwate University, 4-3-5 Ueda, Morioka 020-8551, Japan
}

(Received August 8, 2013; accepted November 8, 2013)

Key words: deep-reactive-ion etching (DRIE), gradation exposure, silicon mold, micro-electromechanical systems (MEMS), microneedle

The purpose of this research is to demonstrate a methodology for etching silicon to particular required depths that can be used when designing structures to manufacture microneedles. A photolithography technique was demonstrated using gradation exposure and deep-reactive-ion etching (DRIE). The entire photolithography process was carried out in two steps: (i) a photoresist pattern was transferred onto silicon dioxide using a layout mask, and (ii) a silicon mold was formed using exposure through the use of a gradation mask and DRIE. A digital gradation mask design that included 16 scales was proposed. The exposure time and thickness of the photoresist were optimized experimentally under 102 different conditions. The aspect ratio of the resist reached 19:1 and the maximum etched depth was $285 \mu \mathrm{m}$ under conditions of $6 \mathrm{~s}$ exposure time and $3 \mu \mathrm{m}$ thickness of the photoresist. It was demonstrated that the slopes formed by deep etching ranged between $0-285 \mu \mathrm{m}$, which is needed for microneedles to be realised by DRIE and grey-scale technology.

\section{Introduction}

Microneedles, which can be used for painless drug delivery or for the semi-invasive collection of blood samples, are being investigated for clinical use.(1) The stratum corneum of human skin has a thickness of $60-200 \mu \mathrm{m},{ }^{(2)}$ so the length of the microneedles needs to surpass this layer by $10-15 \mu \mathrm{m}$ for drug delivery and by $200-400 \mu \mathrm{m}$ for sample collection. ${ }^{(3)}$

The development of micro-electromechanical systems (MEMS) has provided tools for highly precise, reproducible, and scalable methods to fabricate structures of micrometer dimensions. ${ }^{(4)}$ Thus, this lithography-based approach can be used to produce microneedle arrays. Previously, fabrication techniques to manufacture needles out of silicon, metal,

${ }^{*}$ Corresponding author: e-mail: masakiy@iwate-u.ac.jp 
polymer, and glass have been reported, which can be used to form large two-dimensional arrays. ${ }^{(5)}$ It is necessary that the microneedles are manufactured using materials that are superior in terms of biological safety, such as biodegradable plastic, because the risk that they could break cannot be completely overlooked. Silicon is convenient to use as a mold for polymer needles for hot embossing techniques or for nanoimprinting. ${ }^{(6,7)}$

To fabricate microneedles, both deep etching to more than $200 \mu \mathrm{m}$ depth and the realisation of inclined shapes with angles between $12-18^{\circ}$ to the vertical are required simultaneously. Deep-reactive-ion etching (DRIE) can be used to transfer photoresist structures into silicon wafers. In particular, the Bosch process, named after the German company Robert Bosch $\mathrm{GmbH}$, is suitable for perpendicular deep etching. ${ }^{(8)}$ The principal benefit is anisotropic etching when transferring a photoresist pattern onto silicon. ${ }^{(9)}$ A perpendicular deep-etching process has been reported with an aspect (height/ width) ratio (etch selectivity) of over 80:1.(10) On the other hand, grey-scale technology can be used to manufacture inclined shapes, and this has been used for large-area processes..$^{(11-13)}$ However, the reported etched depths that have been achieved when using grey-scale technology only range within $1-10 \mu \mathrm{m}$. As a feasibility study, we have tried to evaluate the effect of exposure time to etched depth on DRIE. ${ }^{(14)}$ At this moment, the optimized fabrication condition cannot be found because the photoresist thickness was not evaluated yet.

The purpose of this paper is to propose a practical photomask patterning method for slope formation by deep etching. DRIE and grey-scale technology are adopted in order to realise both deep etching to more than $200 \mu \mathrm{m}$ depth and inclined shapes that can be used for manufacturing a silicon mold for the formation of micro-needles.

\section{Materials and Methods}

\subsection{Photomask}

A sixteen-scaled grey-scale mask design was proposed to achieve the desired gradation exposure (Fig. 1). The grey-scale mask was pixelated in $4 \times 4$ grids with a pitch of $0.5 \mu \mathrm{m}$. The case where all the grids were black was set as scale 0 , and the case where all the grids were white was set as scale 16. The sixteen-scaled gradation was expressed by reversing one grid at a time. The grey-scale masks were fabricated using an electron beam lithography mask writer (JBX-9300FS, JEOL Ltd., Japan), which was capable of writing nanometer-sized features.

Figure 2 shows the design of a layout mask, which includes both an etched depth evaluation area $\left(100 \times 100 \mu \mathrm{m}^{2}\right)$ and an aspect ratio evaluation area $\left(12 \times 500 \mu \mathrm{m}^{2}\right)$. The ratio of the etched depth to the mask width was defined as the aspect ratio. Seventeen sets of these layout masks were prepared on a silicon wafer. The grey-scale masks were set on each layout mask.

\subsection{DRIE}

Figure 3 shows the manufacturing process of a test piece for slope-form deep etching. The wafer was coated with a positive-type photoresist (OFPR-800, Tokyo Ohka Kogyo Co., Ltd., Japan) using a spin coater (ASC-4000, Actes Inc., Japan). The photoresist was 

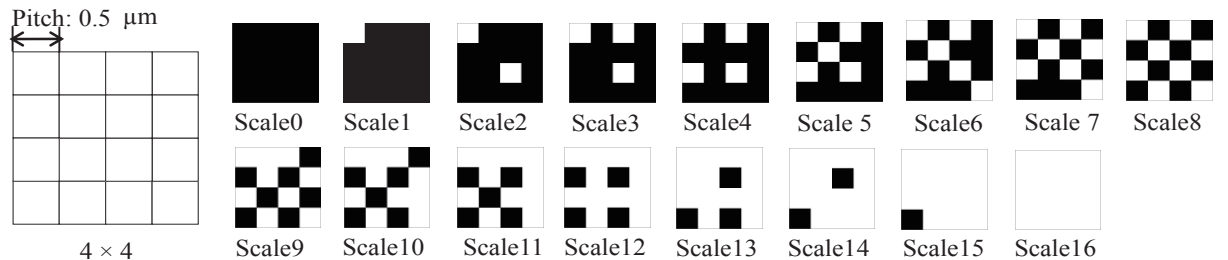

Fig 1. A sixteen-scaled gradation mask design scheme using a basic matrix $(4 \times 4)$ to be used for the test piece for slope-form deep etching.

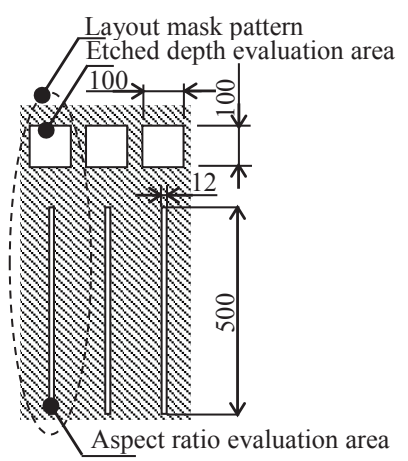

(a)

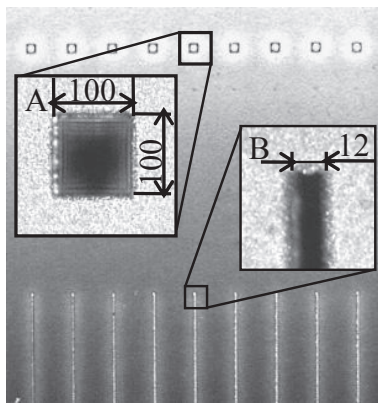

(b)

Fig. 2. A pattern of layout mask used for the evaluation of both the etched depth and aspect ratio on a test piece for slope-form deep etching. (a) Designed layout mask and (b) Fabricated layout mask.

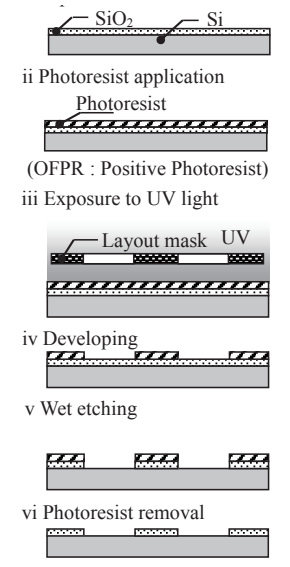

(a)

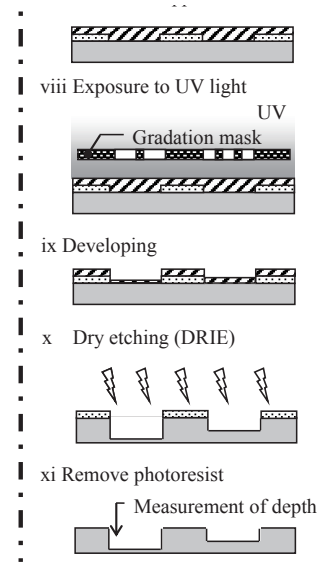

(b)

Fig. 3. Photolithography of the test piece for slope-form deep etching including a two-step exposure process (a) process using the layout mask and (b) process using the gradation mask.

exposed to a pattern using the layout mask and a mask aligner (MA6, Suss MicroTec KK, Japan). The silicon was liquid (wet)-etched to remove the unprotected oxide. The photoresist was removed from the substrate using a resist stripper.

The second photoresist layer was exposed for various times $(6,9$, and $12 \mathrm{~s})$ at an 
intensity of $47.9 \mathrm{~mW} / \mathrm{cm}^{2}$ using the gradation mask. DRIE was performed for $120 \mathrm{~min}$ using a Si DRIE system (MUC-21, Sumitomo Precision Co., Ltd., Japan). Finally, the photoresist was removed using acetone and the $\mathrm{SiO}_{2}$ was removed using hydrogen fluoride. The thickness of the photoresist was set to 3 or $7 \mu \mathrm{m}$ (Table 1).

\subsection{Measurement}

The arithmetic average roughness, $R a$, and etched depth, $d$, were measured using a noncontact three-dimensional displacement measuring system (NH-3SP, Mitaka Kohki Co., Ltd., Japan). A total of 102 measurements of the etched depth were carried out for the 17 grey-scale levels, 2 different thicknesses of the photoresist, and 3 different exposure times.

\section{Results and Discussion}

Figure 4 shows a measured result of the surface roughness of the test piece in the roughness evaluation area under the condition of 3- $\mu \mathrm{m}$-thick photoresist, $6 \mathrm{~s}$ exposure time, and scale 7. The $R a$ ranged between $1.59-1.87 \mu \mathrm{m}$ in the etched depth evaluation area (Fig. 4), and $d$ was $189 \mu \mathrm{m}$ under these conditions. The variation of $R a$ over $d$ was calculated to be $1 \%$ or less. The variations of $R a$ were kept under $1 \%$ in all of the experimental conditions. It was revealed that the etched bottom was formed evenly.

The absolute values of etched depth were greater than $250 \mu \mathrm{m}$ under each condition. A linear approximation expression for the etched depth was calculated using the least-

Table 1

Conditions of spin application of photoresist and bake length of a test piece for slope-form deep etching.

\begin{tabular}{|c|c|c|c|c|}
\hline Thickr & ess of photoresist & $\begin{array}{l}\text { Spin application } \\
(\mathrm{rpm})\end{array}$ & $\begin{array}{l}\text { Prebake time } \\
\min .\left(120^{\circ} \mathrm{C}\right)\end{array}$ & $\begin{array}{l}\text { Postbake time } \\
\min .\left(120^{\circ} \mathrm{C}\right)\end{array}$ \\
\hline $3 \mu \mathrm{m}$ & & 2,000 & 6 & 12 \\
\hline \multirow{2}{*}{$7 \mu \mathrm{m}^{*}$} & First application & 2,000 & 3 & \multirow{2}{*}{12} \\
\hline & Second application & 3,000 & 10 & \\
\hline
\end{tabular}

${ }^{*}$ Two coats

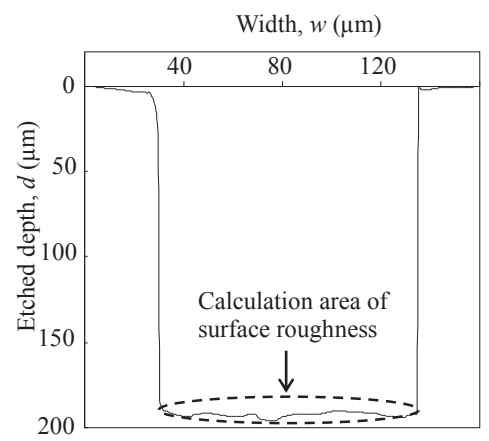

Fig. 4. Measured result of the surface roughness of the test piece in the etched depth evaluation area. 
squares method between the point at which the etched depth begins to change and the point at which it reaches $90 \%$ of the saturation value. It was clear that the slope between the etched depth and the scale of gradation could be made smaller by shortening the exposure time [Fig. 5 (a)]. However, the slope was decreased in proportion to the thickness of the photoresist; the slope of the 7- $\mu \mathrm{m}$-thick photoresist showed 33.5 [Fig. 5 (b)]. Then, the slope was minimized under the condition of $6 \mathrm{~s}$ of exposure time and $3 \mu \mathrm{m}$ thickness of the photoresist. In summary, it was shown that the etched depth was $287 \mu \mathrm{m}$ at 11 scales; thus, a rate of $26 \mu \mathrm{m} / \mathrm{scale}$ was realised under this condition. The linear approximation equation between the etched depth, $d$, and the scale of gradation, $S$, is shown as follows:

$$
d=29.1 S-11.3(\mu \mathrm{m}) \text {. }
$$

The aspect ratio was evaluated using the aspect ratio evaluation area. The width remained approximately constant without depending on the etched depth in DRIE. Then, the aspect ratio ranged between 18.3 and 18.8 in the aspect ratio evaluation area. The

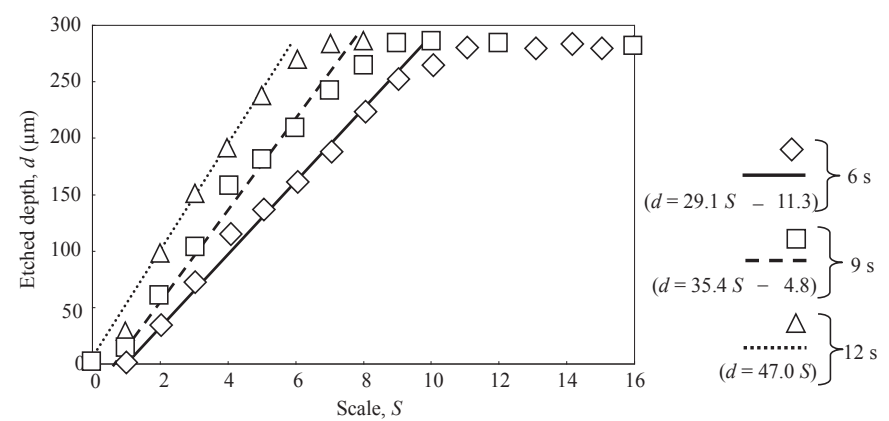

(a)

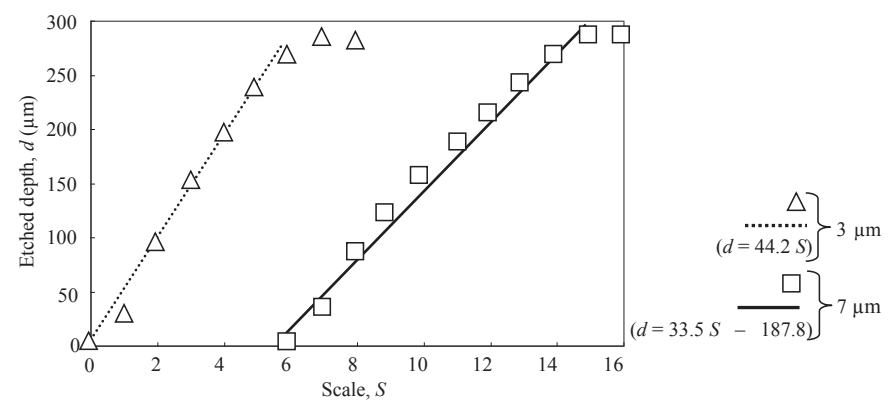

(b)

Fig. 5. Measured photoresist profile using the sixteen-scaled gradation mask and DRIE. (a) $3-\mu \mathrm{m}$-thick photoresist and (b) $12 \mathrm{~s}$ exposure time. 


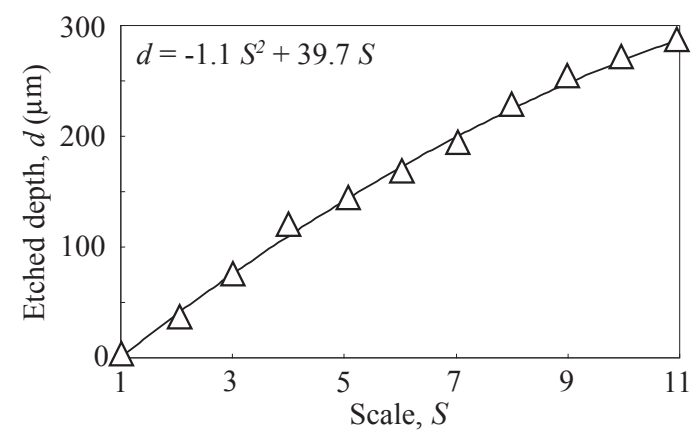

Fig. 6. Approximation of relationship between etched depth and scale of gradation exposure and photomask patterning for a slope form (6s and $3 \mu \mathrm{m})$.

aspect ratio was not affected by the exposure time or the thickness of the photoresist. The maximum etched depth showed $225 \mu \mathrm{m}$, then the width was $12 \mu \mathrm{m}$. Thus, the aspect ratio was calculated up to $225: 12 \cong 19: 1$. Since the mask width was as narrow as $12 \mu \mathrm{m}$, it was considered that a microloading effect was one of the reasons why the aspect ratio did not reach 80:1. ${ }^{(15,16)}$ When the aspect ratio increases, the etching rate falls and both relations will not show a direct proportion.

To consider the microloading effect, a quadratic approximate equation can be used. Under the condition of $6 \mathrm{~s}$ exposure time and $3 \mu \mathrm{m}$ thickness of photoresist, the quadratic approximate equation between $d$ and $S$ can be shown as follows (Fig. 6):

$$
d=-1.1 S^{2}+39.7 S(\mu \mathrm{m})
$$

The etched depth can be controlled between 0-285 $\mu \mathrm{m}$ by applying eq. (2) for the patterning of the gradation mask. This characteristic is suitable for the manufacture of a silicon mold to produce microneedles.

\section{Conclusion}

A sixteen-scaled grey-scale mask design to be used for gradation exposure was proposed and the exposure time and thickness of the photoresist were optimized in DRIE. The aspect ratio of the resist reached 19:1, indicating that the etched depth could be controlled between $0-285 \mu \mathrm{m}$. Thus, a quadratic approximate equation was drawn experimentally, which is suitable for the manufacture of a silicon mold to form microneedles.

\section{Acknowledgements}

Part of the fabrication of the grey-scale mask was supported by Hiroshi Fujita and Naoko Kuwahara, Research \& Development Center, Dai Nippon Printing Co., Ltd., Japan. Part of the fabrication of the test pieces was supported by Associate Professor Kentaro Totsu, Hands-on Access Fabrication Facility, Tohoku University, Japan. 


\section{References}

1 W. H. Smart and K. Subramanian: Diabetes Technol. Ther. 2 (2000) 549.

2 T. Nishikawa ed.: Standard Textbook of Dermatology (Igaku Shoin Ltd., Tokyo, 2007) p. 7 (in Japanese).

3 R. K. Sivamani, B. Stoeber, G. C. Wu, H. Zhai, D. Liepmann and H. Maibach: Skin Res. Technol. 11 (2005) 152.

4 M. Esashi: J. JSTP 44 (2003) 4 (in Japanese).

5 D. V. McAllister, P. M. Wang, S. P. Davis, J. H. Park, P. J. Canatella, M. G. Allen and M. R. Prausnitz: Proc. Natl. Acad. Sci. U.S.A. 100 (2003) 13755.

6 M. T. Koesdjojo, Y. H. Tennico and V. T. Remcho: Anal. Chem. 80 (2008) 2311.

7 S. Y. Chou: United States Patent No. 5,772,905 (1998) 14p.

8 F. Laermer and A. Schilp: United States Patent No. 5,501,893 (1996) 6p.

9 X. Li, T. Abe, Y. Liu and M. Esashi: J. Microelectromech. Syst. 11 (2002) 625.

10 B. Morgan and C. M. Waits: J. Microelectromech. Syst. 13 (2004) 113.

11 C. M. Waits, A. Modafe and R. Ghodssi: J. Micromech. Microeng. 13 (2003) 170.

12 C. M. Waits, B. Morgan, M. Kastantin and R. Ghodssi: Sens. Actuators, A 119 (2005) 245

13 K. Totsu and M. Esashi: J. Vac. Sci. Technol. B 23 (2005) 1487.

14 M. Yamaguchi, Y. Sasaki, Y. Kimura and M. Sasaki: Pacific Rim Meeting on Electrochemical and Solid-State Science (PRiME2012), ECS Transactions: Chemical Sensors 8 (2012) 67.

15 C. Hedlund, H.-O. Blom and S. Berg: J. Vac. Sci. Technol. A 12 (1994) 1962.

16 S. Jensen and O. Hansen: Proc. SPIE 5342 (2004) 111. 